\title{
Work as Community: Narratives of Solidarity and Teamwork in the Contemporary Workplace, Who Owns Them?
}

\author{
by Gillian Vogl \\ Macquarie University \\ Sociological Research Online 14(4)4 \\ <http://www. socresonline.org.uk/14/4/4.htm/> \\ doi:10.5153/sro. 1933
}

Received: 7 Oct 2008 Accepted: 19 Jun 2009 Published: 31 Aug 2009

\begin{abstract}
The workplace provides a very important context for the development of community. Structural changes that have occurred in the workplace in the last 25 years have impacted on how community has been constructed and experienced in the workplace. These structural changes have often been accompanied by particular types of organisational cultures and forms of work organisation. One such form of work organisation has been teamwork. Some have argued that management induced forms of employee collectivism, such as teamwork have undermined more genuine employee generated forms of community and solidarity. Through in-depth interviews with employees in a number of organisations from two research projects, this article explores employee's experiences of community and highlights the different ways in which teamwork is interpreted and experienced by workers.
\end{abstract}

\section{Keywords: Qualitative Research Methodologies, Workplace, Organisational Culture, Teamwork, Manufactured Community, Community, Solidarity, Post- Fordism, Fordism}

\section{Introduction}

1.1 The workplace provides a potential site for the development of community. Within many workplaces people are forced to interact with one another on a day to day basis and this interaction often goes past a superficial mixing and allows for the potential development of much stronger bonds. For advocates of forms of work organisation, such as teamwork, teamwork is seen as a potential context for the development of community and solidarity among workers. Contrary, to this view, for critics of teamwork, teamwork is viewed as undermining a genuine sense of community and relatedness in the workplace.

1.2 Teamwork refers to an "interdependent collection of individuals who share responsibility for specific outcomes of their organization" (Scarbrough and Kinnie 2003:135). Through exploring workers' narratives of community in their workplaces, this article explores the following research question: To what extent do management induced forms of work organisation, such as teamwork, undermine more genuine forms of workplace community and solidarity?

1.3 The research described below focuses on how changes to forms of work organisation, namely the emergence of teamwork impact on how employees experience community in the workplace. The researcher chose a number of different types of workplaces and recruited a sample of both working and middle class people in different kinds of blue and white collar occupations from both privately and publicly owned workplaces, in order to compare and contrast how teamwork was experienced in different types of workplaces. Not all employment relations are capitalist in a capitalist society and thus there needs to be a realisation of the difference between these employment relations. However, this does not mean that state sector employment relations should be disregarded, as both of these types of workplaces are shaped by macro capitalist workplace changes (Thompson 1990) and therefore employees from both private sector and state sector workplaces were interviewed in this study.

1.4 The researcher was interested in not only considering how macro workplaces changes had impacted on community but also how micro work processes and the nature of people's work, interact with more macro workplaces changes to influence how employees experience community in their workplaces. The following section provides a background for the context in which teamwork as a form of work organisation has 


\section{Background: From Fordism to Post-Fordism - The emergence of teamwork}

2.1 In the last 25 years in Australia and globally, the labour process has gone through some major changes. While the way work has been organised has not followed a linear pattern and historical analysis and research on different economies points to diversity rather than a single similar development in the labour process (Littler 1990), in particular phases of capitalism, some forms of work organisation have become more prominent than others. This is true also of management control and styles (Thompson 1990). There are a number of types and forms of management control that are often combined and implemented within the same time frame.

2.2 However, while there has been no homogenous linear transformation to the labour process with regard to work organisation, management control, or types of workplaces, there are general trends that have occurred in the last 25 years, of which much has been written. These trends have influenced how community has been constructed and experienced in the workplace and who constructs this community. Community refers to the development of bonds between a group of people working in close proximity to one another or feeling a sense of unity with one's co-workers.

2.3 Contemporary workplace changes have been characterised as a move away (in rhetoric at least) from Fordist type structures to Post- Fordist structures. Taylor's Principles of Scientific Management were published in 1911, at which time Taylor estimated that in America more than 50,000 workers were working under this form of work organisation. One of his principles, the separation of manual and mental labour, became a feature of mass production techniques and is still carried out in many factories today (Beder 2000). Henry Ford, who established mass production in the motor industry extended Taylor's methods by replacing people with machines to carry out certain tasks. One of these machines was the conveyer belt, which meant that management could decide the speed upon which workers should assemble cars as the cars were brought to the workers. Prior to Ford's creation of big factories, the car industry was characterised by a number of shops containing a highly skilled autonomous workforce who carried out many complicated tasks within a single working day (Sennett 1998). Ford's mass production of standardised goods was imitated by many others as it became much more profitable than the craft based production described above (Bradely et al. 2000). Ford used a form of work organisation that came to be termed JIC (just in case) which involved the mass production of standard products. This meant that if there was a break down in the system there was always a build up of stock and the factory could continue to function (Bradely et al. 2000). Ford fragmented jobs into very small parts (Beder 2000), preferring to employ specialist workers whose work was very routine and involved little skill (Sennett 1998, Beder 2000). These workers were rewarded for their boredom through relatively high wages (Sennett 1998).

2.4 The type of production titled JIC, discussed above and which characterised the 'Fordist era', came to be seen as wasteful. Due to the success of Japanese industries, experts turned their attention to Japan. As a result, a body of expertise developed linking Japanese success to Post -Fordism and lean production (Bradely et al. 2000). JIC was surpassed by a more flexible type of production known as JIT (just in time). JIT is a flexible system where parts, workers and supplies arrive at the production process just as they are needed. In order for this system to work, managers need to have an excellent knowledge of the overall details of production and this knowledge had to be shared with a team who work co-operatively with one another (Bradely et al. 2000). Flexible specialisation aims at getting a variety of products onto the market as soon as possible (Sennett 1998). The speed with which modern communication works, privileges this type of work organisation, as data from the global market is easily accessible to companies. Within this type of production there is a need for quick decisions and thus the construction of small teams are important. Previous bureaucratic hierarchical forms of work organisation slow down this process. Within this process, demands in the market determine what goes on inside the work organisation (Sennett 1998). Lean and flexible work is presented as mutually beneficial for employees and their workplaces.

2.5 According to Miller and Rose (1990), within Taylorism the worker was characterised as being a passive subject motivated solely by money. In Britain, during the inter war years, a new way of considering workers was developed through the work of Charles Myers and the National Institute of Industrial Psychology. Within this Human relations approach the worker came to be considered as an agent who was both rational and emotional. The individual was perceived to be both a worker and a family person. Those within the London based Tavistock Institute of Human Relations believed that workers needed to be placed in groups where they could complete a whole task (Beder 2000). A Quality of working life (QWL) programme was promoted as enhancing both the lives of employees and improving workplace efficiency and was developed as a result of a link between Tavistock and democratic corporate rationales, which originated from some Scandinavian countries in the 1960's. By the early 1970's QWL was being viewed positively by employers, critical scholars and activists. Themes such as, job enrichment, job rotation, teamwork and employee participation suggested a form of work organisation which would improve employee well-being and empowerment. As a result of finding meaning in their work, workers would relate to the product they were producing and perceive their own worth to be tied up with and reflected in the quality of the work which they produced (Rose 1990). Subsequently, critics of these approaches claimed that Quality of working life and Human Relations had been developed to undermine the power of unions and were used to pacify workers (Rose 1990).

2.6 Thus, the extent to which Post-Fordism and the types of work practices and cultures associated with Post-Fordism have benefited employees is contentious. Post-Fordism has been associated with a flattened out hierarchy, self- regulating teams, employee participation, good communication, interpersonal and problem solving skills and increased employee autonomy and empowerment (Rifkin 1995, Connell 1998, Sennett 1998) and some workers have benefited from workplace changes. However, for most, the pressure to cut costs in private and public organisations (Warhurst and Thompson 1998) has resulted in a contemporary workplace which has come to be associated with: outsourcing, the rise of less secure work, 
work intensification, increased surveillance, an attack on the collective rights of workers, an undermining of centralised wage bargaining, a reduction in pay, and for some the removal of penalty rates and the elimination of overtime allowances (Watts and Hubbard 1996, Hall 2007). In addition, while lean production signalled the coming of a Post -Fordist era, this form of production has not been applied universally or in a uniform way. In many workplaces, labour is still monotonous and repetitive (Sennett 1998, Bradely 2000).

2.7 In an attempt to make negative workplace changes more acceptable, many of these changes have been accompanied by organisational cultures imposed on employees by management. In many contemporary workplaces, it has been perceived to be management's role to develop a particular type of workplace culture. Much has been written about organisational cultures (Miller and Rose 1990, Rose 1990, Kunda 1992, Casey 1995, Du Gay 1996, Hochschild 1997, Connell 1998, Stranglemen and Roberts 1999, Ezzy 2001). Modern forms of work organisation, such as JIT (Just in Time), TQM (Total Quality Management) and HRM (Human Resource Management), all differ in ways but are common in that they all impact on social relations in the workplace. According to Casey (1995), a new culture embodying the rhetoric of team and family and a shared company philosophy has been developed in order to make these changes more acceptable and to provide an alternate sense of community to replace more traditional worker organised solidarities. Teamwork has been one of the prominent forms of work organisation to emerge from the introduction of lean production techniques.

2.8 Those who support teamwork as an important form of work organisation suggest that teamwork empowers employees through giving them increased control over their work. Teamwork is seen to result in employees being able to make better use of their skills and in feeling more committed and positive towards their workplaces. Teamwork is seen as providing outcomes which are far superior to what individuals can achieve in non-team contexts. Teamwork has also been viewed as providing the potential for the development of positive peer relations where work colleagues care for one another, are more committed to one another and can have fun together. This co-operation leads to greater workplace productivity and achievements which in turn leads to higher self-esteem for the employee (Harley 2001, Tarricone and Luca 2004).

2.9 While advocates for teamwork view teamwork as providing this potential for community, others view teamwork as undermining a genuine sense of community in the workplace. Critics of teamwork have argued that while teamwork may empower management, it essentially results in work intensification for employees (Harley 2001). Management provides the final say and the framework, usually through understated team pressure where employees continually reinforce in one another the appropriate organisational behaviour (Casey 1995 and Kunda 1992). The form of community that teamwork potentially provides mimics the cohesiveness of traditional industrial culture while undermining resistance to structural conflicts that are inherent in the contemporary workplace. The aim of corporate culture is to undermine other forms of solidarity that are not in the interests of the corporation, such as unions. Teamwork provides a manufactured social space which meets peoples' needs for community while simultaneously undermining any forms of solidarity which may lead to resistance against the company (Casey 1995)

2.10 Both Sennett (1998) and Ezzy (2001) argue that company manufactured forms of community, such as teamwork, represent the cleansing of all that is real and genuine in relationships. Teams as a form of work organisation have no visible form of authority but rather more surreptitious forms of peer discipline. This obscures for employees the reason that they feel the constant need to prove themselves. In order for teams to perform well, there needs to be co-operation between members. For this co-operation to occur, companies hide the extent to which employees are in fact in competition with one another. Ezzy (2001), claims that the freedom of choice that engineered cultures claim to provide are in fact limited to choices within a framework which produces individuals who end up with a very self-absorbed attitude towards others, both in and outside the corporation. This form of work organisation has led to an undermining of worker generated collectivism and to a rise in individualism. Ezzy (2001) claims that, even resistance to this all pervasive culture is carried out in an individualistic and instrumental way, leaving little room for a focus on social relationships which exist more collectively. The incredible demands on individual's time often leaves little room for the development of an identity outside the workplace and an interest in others only becomes valued if it helps to enhance the individual's careers or the efficiency of the workplace (Ezzy 2001).

2.11 According to Sennett (1998) the modern work ethic with its focus on teamwork, emphasises soft skills such as empathy, co-operation and adaptability and these skills obscure the power relations that exist within this form of work organisation. Casey (1995) claims work organisation in the form of teamwork secretly encourages nepotism and mistrust while it openly encourages equality, co-operation and commitment. Bellah et al. (1985), claim that intimacy in the form of the language of therapy is used to make teams cohesive. Intimacy is used as a work strategy and thus being sensitive and caring becomes a necessary part of the job. This may provide a more humane work environment or at least the illusion of a more humane environment but is enacted in order to achieve instrumental gains.

2.12 Many workers place importance on community in the workplace, seeing work as a basis for community and social life (Pocock 2003) The importance of the workplace as providing a sense of community and camaraderie has been well documented in the past (Deyo 1980, Cavendish 1982, Fine 1986, Marks 1988, 1994a, 1994b, Hochschild, 1997, Boas 2001). Casey (1995) claims that teamwork simulates a sense of belonging, being cared about and nurtured. The notion of teamwork is also used to eradicate the power of trade unions and prevent dissent or resistance to work intensification as individuals who complain are portrayed as not being team players (Beder 2000). Teamwork is the pretence of community.

2.13 In an article exploring what teamwork means for employees working within an automobile manufacturing company, Knights and McCabe (2000) are critical of both the accounts of advocates for teamwork and the critics of teamwork. They argue that for employees, there is no single experience of 
teamwork and employees are able to use their agency to interpret and re-interpret management strategies to both commit to and resist management narratives about teamwork.

2.14 Lucio and Stewart (1997) claim that while teamwork may have been developed in the interests of capital there is evidence in a number of industries that employees' are also able to view these collective work structures in a different and collective way from managers. Due to an over-emphasis in contemporary theories on the workplace on the dominance which management has over knowledge, labour as an agent has been marginalised.

2.15 Plankey's (2006), ethnographic study of a garment factory in Mexico demonstrated how employees used teamwork to develop an alternative sense of community through which they were able to arouse resistance towards the factory. Lean production based on teamwork was introduced into the company in the 1990's and in order for it to be successful managers introduced a 'community of fate' between employees and managers. This discourse suggested that managers and employees interests were closely aligned and in the interests of the company. The development of loyalty and trust between the company and the workers was fostered through paternalistic services that the employer provided to workers such as, free dental care for their families. During times of economic downturn, workers endured sacrifices due to their adherence to a 'community of fate'. However, this changed when managers reneged on a deal that they had made with employees. The employees found that teamwork provided them with a structure that encouraged collective alliances among workers and proceeded to use this structure to collectively undermine the company.

2.16 The following research explores the extent to which company induced forms of community undermine more genuine informal types of community and highlights the different ways in which teamwork is interpreted and experienced by workers. The next section details the methodological approach which was taken in this research.

\section{Methodology}

3.1 Qualitative research methods were used to gain and analyse the data in this study. While data for this study was drawn from two research projects, the majority of the data was drawn from the first project. The first study involved 47 in-depth interviews obtained through purposive and snow ball sampling with men and woman in a range of blue and white collar occupations in NSW, Australia, from both publicly and privately owned workplaces between 2000 and 2001. The workplaces included; a School, Careers and Counselling Service, Pharmaceutical Company, two Information Technology Companies, Insurance Company, Cafe, large Retail Store, Ambulance Service, Steel Company, Building Site, Night club and the Waste Disposal section of a local Council.

3.2 The second project undertaken with $\operatorname{Dr}$ Amanda Wise in 2005 focused on intercultural relationships. While the research in this project was not focused on the workplace and community as such, the workplace emerged in this project as a very significant site for both the development of intercultural relationships and conflict. Therefore some of the data from this project has been useful for adding richness to the findings in the first project. The sample in the second project involved 53 participants from diverse cultural backgrounds working in a number of workplaces in a regional town in NSW in Australia.

3.3 The interviews lasted between twenty-five minutes and three hours, with the average being an hour. Most of the working class participants participated in the interviews in their own time, either in the researcher's home or at their home. The majority of middle class participants did the interviews in 'work time' at their workplaces. The next section discusses the findings that emerged from this research.

\section{Findings}

4.1 While some social theorists have argued that forms of top down work organisation, such as teamwork undermine more genuine forms of community and solidarity in the workplace (Sennett 1998, Ezzy 2001), others, view teamwork as providing a platform for the development of community (Tarricone and Luca 2004) and alternative forms employee generated solidarity (Lucio and Stewart 2006, Plankey 2006). The findings from this research highlight the different ways in which employees interpret and experience teamwork and the impact these perceptions and experiences have on worker's sense of solidarity and community in their workplace. Only a few participants who were interviewed talked about a sense of community in a more general sense. However, many talked about the importance of community in their own lives.

4.2 Some of the organisational cultures that were specific to particular places of employment and the nature of the work people did meant that some workplaces were more conducive to the development of informal community than others, yet community existed across all public and private sector workplaces and was experienced by both blue and white collar workers. A sense of community in the workplace seemed to be important to the majority of participants in this study.

4.3 For more than any other occupational group in this study, the teachers were the most focused on their 'out of work' social relationships, many did however talk about the importance of community in the workplace. One participant stated that, "if some people require intimacy to help them get through the day and work becomes part of their social, then I guess it could be important", and another claiming that "having friendships, I don't think you could avoid, I mean if all you are doing is relating to your colleagues in a totally dry, professional basis, I think it is a very dehumanising environment" and another "it kind of makes you look forward to coming in here on a Monday morning".

4.4 There was not a lot of socialising among teachers across staff rooms but a few of the teachers believed that there was a basic sense of community among teachers in general, as at the time the 
interviews were carried out, teachers had just been through a massive industrial campaign. This had led to an attack on teachers by the government and media and a resulting negative public perception of teachers. The persecution of teachers by the public as a result of how they were portrayed by the media led to the creation of an informal sense of community and solidarity among the teachers. Other teachers also mentioned camaraderie among staff within particular staff rooms. Wendy, a head teacher, spoke of the "nice camaraderie that we have formed in here", another spoke of being short staffed within his staff room, which created solidarity among those who were left. This teacher also spoke of a "smoker's corner", in the car park where staff got together to have a chat. While, he was a non-smoker, he occasionally went to the smokers' corner for a chat.

4.5 In the careers and counselling service, friendships were facilitated through teamwork, going out collectively for informal lunches, having peer support sessions and an embedded belief in reciprocal disclosure.

\subsection{Nicole, a Clinical Psychologist, stated that:}

I think in a lot of ways having intimacy with people that you work with is vital. To feel connected to people that you are working with. I would hate to work somewhere where I wasn't able to share how I feel about a particular issue or nothing in particular. I think that is one of the great things working with people who are people orientated and that adds something to the work. It gives you cohesion with the people that you are working.

4.7 In the regional town in Australia, the workplace provided a very important context for newly arrived migrants and refugees to mix with people who were not from their own cultural backgrounds. Participants from this study, talked about how they found out about things that were happening in the community through work. An Afghani woman spoke of how she enjoyed her work, partly because she had made lots of friends through work from Vietnamese, Pilipino, Australian, Russian and Tongan backgrounds. She said that everyone talked during their breaks. An Indo Fijian woman who worked in a packing shed talked about how she gradually got to know workers from other cultural groups to the point where she had now exchanged home phone numbers with many of the women she worked with.

4.8 At the retail store, while unity among workers was constantly undermined by work intensification, job insecurity and management, workers still experienced a sense of community. Cindy, who worked as a Night Filler, said that there was community among some of the mothers because of the commonness of their situation, since a lot of these women were at home with their children all day and then when their husbands come home from work, they went off to work. "Most of the mums tend to stick together." A number of the working class participants also raised the issue of community. Jack, a garbage truck driver, described the social relationships in his workplace in the following terms:

Most of them have been there for a long time and known each other for a while so it is a bit of a mateship in that sense. Although you will find that a few of the sections stick together in a little way so, the recyclers stick with the recyclers and the garbage truck drivers stick with the garbage truck drivers.

4.9 Thus while the majority of employees were able to enjoy positive relationships in their workplaces as indicated from the above quotes and that this occurred even for those workers where management purposely tried to undermine solidarity among workers, critics of teamwork have argued that teamwork, while mimicking a sense of community, in order to meet the needs for relatedness among employees, in reality, undermines the potential which employees have to experience a genuine sense of community.

4.10 While teamwork existed in all the workplaces, manufactured cultures were much more apparent in some of the privately owned corporations and among the participants whose experiences were largely middle class. Many used similar buzz words talking about "self-actualisation" and in the modern dynamic workplace "embracing change" and "reinventing yourself". In order to cope with work intensification, "working smarter, not harder" was used by a number of the employees in the insurance company. This put the onus of coping with the work onto the individual and thus did not question why there was such a great workload in the first place. Some of the participants in the insurance company also talked about "managing upwards" in order to make the managers seem more acceptable to their own subordinates.

4.11 While some of the workplaces in this study appeared to have strong organisational cultures which worked to bond employees to their workplaces, other workplaces didn't appear to have strong workplace cultures and workers were very aware of the antagonistic relationship between capital and labour.

4.12 Irene, who worked in security checking customers bags as they left the store, when asked how she felt about her work stated:

The work load has tripled, the conditions are worse, if you dropped dead, they wouldn't even bother to replace you, they would just sweep you up and let your body rot

4.13 Both the participants from the insurance company and the pharmaceutical company seemed to have internalised a specific workplace culture more so than any of the respondents from the other workplaces. The participants from these companies frequently used the same words or phrases to describe work processes or expectations. These participants also frequently mentioned the importance of "work/life" balance.

4.14 Most of the staff at the American owned Pharmaceutical Company which had received a number of awards for being an excellent employer to work for, had internalised the organisational culture of this company. Tanya, an administration assistant, claimed that it was standard across the company that one 
just followed the same "core values in your working life" that one did in their personal life which were "integrity, communication and teamwork". The culture which had been constructed by the pharmaceutical company was very internalised by many of the employees in this company, surprisingly, particularly by those who occupied lower level positions. While this culture may have been created in the self-interest of the company, employees there felt as though their loyalty to the company was reciprocated.

4.15 The respondents who worked at the pharmaceutical company appeared to be the happiest with their workplace out of all the participants in this study. A culture of friendliness was encouraged at the company, with the words 'teamwork, integrity and communication' mentioned frequently. Tanya, a married administration assistant, who travelled a long distance to get to work because she liked working for the company so much, said that:

When I first started here, Gillian, I went home to my husband and said "God, they are all like Smurfs, they are all walking around, they are really happy! It was a huge change from the company that I came from last time. It was predominantly male. I don't think there were any female managers and it was very structured. We will do this today sort of thing. I mean we do have a lot of women in management here but I think that it is essentially the culture that has been formed here. It's what the company instils as their core values that we live by here.

4.16 Many employees had also internalised the company vision of teamwork, particularly if this did not contradict with their lived experiences in a significant way. Teamwork was seen by many of the participants in this study as effective for both the employee and the company. Employees from both the private and the public organisations believed that being a good team player was a vital quality they needed for success in their jobs. Participants stated that it was important to be, "aware of the greater good", "part of a team", "use a team approach", a good worker is someone who "is a good team player".

4.17 Respondents also talked about how those who did not approach their work with a team spirit could be detrimental to others. One of the team leaders I interviewed said that he had worked on projects where one person had destroyed the whole team balance. In his view it was imperative to quickly identify the "bad apple" and do something about it in order for the team to achieve their goals. It can be ascertained through many of the comments made by participants in the study that how well the team performed as a whole was more important than the well-being of the individual team members. Teamwork did create a context where employees felt compelled to scrutinise and discipline their co-workers.

4.18 The administrative staff at the school had experienced work intensification, which meant that they had to co-operate with one another to get their work done. Relationships became strained among staff that appeared not to be doing their full workload or that "bit extra", as this made things harder for everyone else. Instead of feeling resentful towards the school hierarchy or education department for increasing workloads or lack of staff, it was workers "who did not do that bit extra" who were viewed as the problem. This was the same, at the Cafe, where hospitality workers relied on each others' good will in terms of staying on after their shifts were finished to cope with their intensified work environments.

4.19 Thus, as suggested by the critics of teamwork, teamwork did result in work intensification with managers providing the final say, usually through understated team pressure where employees continually reinforced in one another the appropriate organisational behaviour (Harley 2001, Casey 1995 and Kunda 1992). Teamwork appeared in the above cases to be subversive to the development of positive relationships among employees, who felt the need to discipline one another for not doing extra work in order for the team to achieve its outcomes.

4.20 However, while evidence from this research suggests that many employees internalised teamwork in similar ways to their managers, employees also viewed teamwork in different ways from their companies. As Lucio and Stewart (1997) and Knights and Mccabe (2001) and Plankey (2006), claim employees are able to view teamwork in different ways from management. While the advocacy of philosophies such as team principles were meant to encourage collaboration and co-operation and discourage competition in many of the companies and the importance of co-operation was stressed continually, limited opportunities, bonuses, other financial rewards, and promotion, fostered competition among employees. Therese, a very effervescent employee at the insurance company, highlighted this hypocrisy:

That's an interesting question because officially it is not. Officially we are meant to have a culture where we try to shrink competitive behaviour. I think that is a very negative way of treating the whole capitalist framework because the capitalist framework is about scarce resources and it is very much a pyramid kind of a game board with only a few slots at the top and the ones that make it to the top get the highest rewards financially. So, that is the model and the framework. So that is just the rules of the game. I just find it a little bit bizarre that we can say that we are not competitive here and that we don't encourage competitive culture. Whether it is appropriate or not is therefore irrelevant, because it is there and it is the whole way that the world works.

4.21 While teamwork was implemented as an efficient form of work organisation that bonded employees to one another and in the interests of the company, it also had the potential to lead to negative feelings towards management. At the Information Technology Company one of the employees was angry with his company because he had lost one of his team mates with whom he had become friends due to a company restructure and retrenchments.

4.22 Thus as both Sennett (1998) and Ezzy (2001) have argued, teamwork undermines a genuine sense of community and results in employees responding in an artificial manner towards one another. Teamwork was experienced by some of the people very negatively in this study and there was evidence from this research that team members did relate insincerely towards one another. There was a belief among some 
that how well one got along with one's team mates could impact on their careers and thus negative feelings towards team members were suppressed. Close friendships among participants at the Insurance Company tended to be constrained due to a lack of trust. As one of the participants at the Insurance Company stated with regard to her caution about getting too close to anyone who may impact on her career, "I would like to be friends with someone in a different area so that they couldn't possibly bite me in the bum". Participants tended to discuss personal issues related to their "private lives" but were more reluctant to discuss personal issues relating to their "working lives" for fear that this disclosure may damage their careers in some way. One of the other employees in this company, who in part of the interview discussed her friendships with some of her co-workers and superiors, also stated that she did not share "work stuff" due to lack of trust.

4.23 A few participants at various workplaces mentioned underlying tensions with particular team members, with one person stating that she was in a new team and really not enjoying her work as a result of having very difficult relationships with her peers. She did not perceive her team to be co-operative.

4.24 In the careers section of the counselling service, the participants worked together in a very small closely knit team that allowed for the development of strong relationships. However, there was an undercurrent of conflict which was repressed. The reason according to one of the participants was that they worked together in such a closely knit team, and any recognition of this conflict could destabilise the team.

4.25 Many employees also spoke of increased surveillance, mentioning constant reviews and restructures. According to some of the working class participants, surveillance involved using employees to spy on one another. Deb, who worked at the retail store, explained that "surveys were sent around encouraging you to dob on your mates". Mike, an ambulance driver, spoke about the "dog eat dog environment" that had been created by increased surveillance. Heightened surveillance at the Ambulance Service appeared to improve the quality of care in the short-term as people were scared of losing their jobs and so displayed the correct behaviours. However, in reality this increased accountability led to worse care as people were constantly "on edge".

4.26 However, as advocates of teamwork have stated, teamwork can also provide the platform for the development of positive relationships with work colleagues (Tarricone and Luca 2004). For many participants in this study, teamwork did provide a sense of relatedness. For example, Graham who was single and a project manager and worked largely on his own said that there was not a lot of "room for intimacy" in his job. At one stage he had been a federal policeman, and at another stage worked at a computer data warehouse. In both of these jobs he had worked in "close knit teams" and there had been an incredible amount of camaraderie, which he missed in his new job, where it was difficult "even to drag people out for drinks on a Friday night".

4.27 The opportunity for the development of genuine friendship as a result of teamwork was mentioned by some of the participants. Elle's description of her relationship that will be described below exemplified this.

The week before Cheryl started it was just 60 men and me so that was the primary reason for our friendship and probably our survival in this environment. We were all 'work hard and play hard' people. We recognised pretty early on that to belong/be accepted, socialising and having fun was the culture and the way at the company. They used to organise lots of things, parties/freebies; we used to often be drinking to dawn. They had fun competition/games/type things with teams that would compete, eg: pin the tail on the executive, other fun things that created strong teamwork and allowed you to see people outside the work environment.

They termed us 'sin sisters' as we pretty much remained close and consistent friends from a very early stage. We liked the attention from the male perspective. We were seen as 'legends' really good chicks who are low maintenance. One of them, so to speak.

Cheryl and I definitely supported each other and as she was better networked/respected earned her stripes with the business people and I with the IT people. The project was $50 \%$ business and $50 \%$ IT. She was Business and I was IT so there was no direct competition. We were both highly committed.

Cheryl and I used to also exercise together. We also had a few relationships with people on the project. I think this was another strong support/bonding between Cheryl and me- we shared all of this and supported each other during difficult times (seeing the person the next day sort of stuff, and dealing with the heartbreaks).

Ironically, at the beginning we were acting within the parameters of the culture to fit in and then along the way really lost perspective on life beyond work.

4.28 Therese, a human resources manager, described the sense of community that had emerged among a team on which she had worked:

I mean when it came time to go home we had to drag ourselves away from one another because we so enjoyed being in one another's company. This was in my last job and now that, at the time I didn't kind of read about high performing teams and sharing and all that sort of stuff, it was only something that I came exposed to in this current job but now I am in reflection realising what we had there is a good example of a high performing team.

4.29 Both Andrew and Dave who were builders talked about the importance of creating and maintaining friendship among team members. Andrew stated that: 
We weren't friends. They have just come to work and developed friendships. That is the thing that we try and keep running, friendly towards the place because if people don't like each other they are not going to work well together. It has sort of just developed itself. Obviously we go out and have a drink after work. A couple of times a years we put on a do. We are going away in two months for a weekend away, so that builds relationships there you know.

4.30 Critics of teamwork have argued that teamwork undermines employee forms of organised solidarity, such as solidarity through the union. None of the white collar workers in the privately owned corporations spoke of the union as a form of solidarity and resistance on which they relied and a number of blue collar workers who had recently immigrated to Australia were unaware of their workplace rights and talked about experiencing discrimination in their workplaces. A Somoan women who worked in the regional town in NSW, spoke about her lack of knowledge of her workplace rights and how this impacted on her experiences at work.

"Yeah and and another thing, I don't know the law of work, but is not allowed to go to the toilet at the time of work. I think for lunch, we can go to the toilet, but I don't know and I must go to the toilet at nearly 10 'oclock and I come to the toilet because I want to go to the toilet and the supervisor call me 'Hey you! Where are you going?' I say 'I am going to the toilet. I am running over there. When I come back and the supervisor go to the boss and said that one, and he come to me and 'Next time you go to the toilet you tell the supervisor ok' and I didn't know.

4.31 However, those workers who traditionally relied on the union appeared to still do so. Irene, who worked at the retail store, was dismissed from work because she took time off work to have a major operation. It was through her union that she managed to get her job back. Karen, a hospitality worker at the club, told of how one of her co-workers had to get the union involved so that she could be put on 'light duties' as requested by her general practitioner.

A girl that I worked with was pregnant. She wasn't young, she wasn't in her twenties, she was in her thirties. This was her first baby and the doctor said that she was having problems. I can't remember why, a bit of bleeding. She was permanent and she had to go on light duties and they wouldn't give her light duties. So she went to the union and she is within her rights to do that. So the union went to the manager and the secretary and the manager, had a discussion, and she was put on light duties because she had a certificate from her doctor. I know for a fact that they refused to put her on light duties when she had a doctor's certificate. She brought the union in and won it.

4.32 While there was conflict between union and non-union members at the school, it was the union that protected the teachers during the industrial campaign of 1999. Jack, a garbage truck driver, spoke of the importance of the union in making people's jobs permanent. He stated that while there was always a casual pool, the union made an effort to try and make peoples' jobs secure.

4.33 Three out of four women I spoke to at the retail store believed that the best way to solve workplace disputes was through going to their union. Deb, a sales assistant, who worked in a collective way and was very proactive in trying to protect the rights of other workers, stated that:

There's casuals who have worked there for four years, who find all of a sudden that their twelve hours a week has gone to zero. And other young people or someone who is not even in the same industry has been employed, then through usually me as union delegate, we go straight to management, if they don't give the hours back, the organiser is then called in and if they still don't give the hours back they will be taken to the commission.

4.34 None of the white collar participants that the researcher spoke to, who worked in the privately owned corporations, spoke of the union as a form of solidarity or resistance.

\section{Conclusion and Discussion}

5.1 Teamwork developed as the result of the introduction of lean production techniques focused on JIT (just in time) systems which were dependent on a team of workers, working co-operatively with one another. Teamwork also emerged in the context of a Human Relations approach to the quality of workers lives and teamwork was seen as providing employees with a sense of autonomy and empowerment that was crucial for their sense of well being. One the one hand, teamwork has been portrayed as a form of work organisation that empowers workers and allows them to find meaning in their work in a way that previous forms of work organisation have not. Advocates of teamwork view it as providing workers with a context in which they can develop a sense of relatedness to one another which is positive for their overall sense of wellbeing. On the other hand, critics of this form of work organisation argue that teamwork obscures the unequal power relations between capital and labour and results in colleagues behaving insincerely towards one another. The significance of the above mentioned study is that through grounded research in a number of different types of both public sector and private sector workplaces, this research suggests that both the critics and the supporters of teamwork are right.

5.2 This research highlights both the diverse ways in which teamwork impacts on relationships among coworkers and also on how micro processes within in the various workplaces impact on workers experiences of teamwork.

5.3 The employees who adopted the company discourses in a more wholehearted way were those whose day to day experiences of work didn't differ too markedly from the company rhetoric. It has been argued that changes in the workplace have led to the rise of individualism and a decline in collectivism. Implicit in 
this suggestion is that capital, and those who act on behalf of capital are the only group with agency. Interviews in this study suggest that workers were still able to respond collectively and were also able to form an alternate sense of community. This was highlighted in the sense of camaraderie among teachers as a result of negative public perceptions of teachers due to negative media portrayals of teacher during an industrial campaign. Also, not all of the participants appeared to passively internalise the organisational cultures of their workplaces and were able to reinterpret some of the company discourses when they contradicted their lived experiences. This was indicated in the way in which they were aware that they needed to compete with one another to make gains in their workplaces.

5.4 Critics of teamwork suggest that it hides the exploitative relationship between capital and labour. This research suggests that to an extent this was the case, in both the private sector corporation such as the insurance company and the Cafe and in the public sector workplace such as the school. Those who complained or refused to work obsessive hours were viewed by peers as not being good team players. Teamwork also had an individualising impact on team members with people tending not to complain about workloads or other team members for fear of this negatively impacting on their career advancement. A lack of trust and repression of feelings towards team members certainly suggests a lack of genuineness among employees.

5.5 Management did try to undermine worker generated solidarity but workers that had done so traditionally, still relied on unions. The union was crucial for participants from many of the workplaces in protecting their workplace rights. Feeling connected and a sense of relatedness to others in the workplace was very important for the participants in this study. A general sense of community existed across all the workplaces, despite attempts by management in some of the workplaces, such as the retail store, to undermine this community. Some workplaces were more conducive to these types of community than others and there were a number of factors that undermined these social relationships.

5.6 While teamwork may have in cases undermined genuine bonds towards employees, it also led to genuine relationships among employees. Some employees, particularly those who were single and who did not work on teams missed the potential for community that this form of work organisation had provided them with in previous jobs, regardless of its artificiality. Team members formed genuine bonds with one another and one of the employees expressed intense anger towards his company as a result of one of his team mates being made redundant due to a workplace restructure.

5.7 Despite the introduction of teamwork, a very genuine sense of community existed across all of the workplaces and employees' placed great significance on community in the workplace. However, while community is important for providing employees with a sense of belonging and relatedness, there was no evidence from this research that suggested that employees in this study had used the structures that teamwork provides to develop a sense of collective resistance to challenge negative workplace changes. The present economic down turn suggests that many workers are going to experience increased job insecurity and eroded rights and the extent to which teamwork can provide a platform for more collective resistance to destructive workplace changes still needs further exploration. At present management appears very much to own teamwork as a form of work organisation, however, they do not always own the ways in which workers interpret teamwork or the types of social relationships which develop from this workplace structure.

5.8 In addition, while workplaces provide an important sense of community, most people don't stay with the same company for life in the contemporary workplace and thus the workplace as a sense of community is often short lived and transient. Work intensification and 'obligatory' socialising, spill over into 'private time' leaving little time for relationships beyond work. The time spent building workplace community undermines the development of more sustainable forms of community and social relationships outside the workplace.

\section{References}

BELLAH R, MADSEN R, SULLIVAN W.M, SWIDLER, A and TIPTON S.M (1985) Habits of the heart: Individualism and commitment in American life, University of California Press: Berkeley and Los Angeles.

BOAS, S (2001) 'The workplace as a Community: The case of British hotels', Industrial Relations Journal, Vol 12, No 6, pp.45-56.

BRADLEY, H., ERICKSON, M., STEPHENSON, C. AND WILLIAM, S. (2000) 'Myths at Work', UK: Polity Press.

CAVENDISH, R. (1982) Women on the Line. Routledge: London.

CASEY, C. (1995) Work, Self and Society after Industrialisation. Routledge: London and New York.

CONNELL, J. (1998) 'Soft skills: The neglected factor in workplace participation' Labour and Industry. August, Vol. 9, No. 1, pp. 69-90.

DEYO, F. (1980) 'The single female factory worker and her peer group', Human Organisation, Vol. 39, pp. 79-91.

DU GAY, P. (1996) Consumption and Identity at Work. Sage Publications: London.

EZZY, D. (2001) 'A simulacrum of workplace community: Individualism and engineered culture', Sociology, Vol. 35, No. 3, pp. 631-650. 
FINE, G. (1986) 'Friendships in the workplace' in V.J. Derelega and B. Winstead (editors), Friendship and Social Interaction, Springer Valeg: New York.

GRINT, K. (1991) The sociology of work. Polity Press, U.K.

HALL, R (2007) The First Year of Work Choices: Industrial Relations in Australia, Journal of Industrial Relations, Vol 49, No.3, pp. 307-309. [doi:10.1177/0022185607077515]

HARLEY, B. (2001) 'Team Membership and the Experience of Work in Britain: An analysis of the WERS98 data', Work, Employment and Society, Vol 15, No.4, pp.721-742. [doi:10.1177/095001701400438170]

HOCHSCHILD, A. R. (1997) The Time Bind: When work becomes home and home becomes work. Metropolitan Books: USA.

KNIGHTS, D and McCABE, D (2000) 'Human Relations', Bewitched, bothered and bewildered: The meaning and experience of teamworking for employees in an automobile company', Human Relations, Vol 53, No 11, pp.1481-1517.

KUNDA, G. (1992) Engineering culture-control commitment in a high-tech corporation. Temple University Press: Philadelphia.

LITTLER, C.R. (1990) 'The labour process debate: A theoretical review 1974-88', in D. Knights and H. Willmott (editors), Labour Process Theory. Macmillan press: UK.

LUCIO, M. M. and STEWART, P. (1997) 'The paradox of contemporary labour process theory: Rediscovery of labour and the disappearance of collectivism', Capital and Class, Vol. 62, pp. 49-77.

[doi:10.1177/030981689706200104]

MARKS, S. (1994a) 'Intimacy in the public realm: The case of co-workers,' Social Forces, March, Vol. 72, No. 3, pp. 843-859.

MARKS, S. (1994b) 'Studying workplace intimacy: Havens at work', in D. L. Sollie and L. A. Leslie (Editors), Gender, Families and Close Relationships, Sage Publications: California.

MARKS, S. (1998) 'The gendered context of inclusive intimacy: The Hawthorne women and work and at home', in R. Adams and G. Allan (editors), Placing Friendships in Context, Cambridge: UK.

MILLER, P. AND ROSE N. (1990) 'Governing economic life', Economy and Society, Vol. 19, No. 1, pp. 131. [doi:10.1080/03085149000000001]

PLANKEY VIDELA, N (2006) It cuts both ways: Workers, Management and the Construction of a "Community of Fate" on the Shop Floor in a Mexican Garment Factory, Social Forces, Vol 84, No 4, pp. 2100-2120.

POCOCK, B. (2003) The Work/Life Collision. Federation Press: Australia.

RIFKIN, J. (1995) The End of Work. Putnam Publishing Group: New York.

ROSE, N. (1990) Governing the Soul: The shaping of the private self. Routledge: London.

SENNETT, R. (1998) The Corrosion of Character: The personal consequences of work in the new capitalism. W.W. Norton and Company: New York.

SCARBROUGH, H. and KINNIE, N. (2003) Barriers to the Development of Teamworking in UK firms, Industrial Relations, Vol 34, No 2, pp.135-149. [doi:10.1111/1468-2338.00264]

STRANGLEMEN, T. and ROBERTS I. (1999) 'Looking through the window of opportunity: The cultural cleansing of workplace identity', Sociology, February Vol. 33, i. 1 pp. 47-61.

TARRICONNE, P and LUCA, J (2002) 'Employees, Teamwork and Social Interdependence: A formula for successful business, Team Performance Management: An International Journal, Vol 8, No 3/4 pp. 54-59.

THOMPSON, P. (1990) 'Crawling from the Wreckage: The labour process and the politic of production', in D. Knights and $\mathrm{H}$. Willmott (Editors), Labour Process theory. Macmillan Press: UK.

WARHURST, C. and THOMPSON, P. (1998) 'The Hands, Hearts and Minds: Changing work and workers at the end of the century', in P. Thompson and C. Warhurst (editors), Workplaces of the Future, Macmillan Press: London.

WATTS, R. and HUBBARD, L. (1996) 'The Crisis for Unions: Confronting a Post-Fordist Future', Arena, Vol. 24, pp. 16-19. 